\title{
Críticos teatrais em ação: luta e organização política em prol da modernidade cênica brasileira
}

Theater critics in action: fight and political organization in support of modernity scenic Brazilian

Erickaline Bezerra de Lima

Naira Neide Ciott ${ }^{2}$ 


\section{Resumo}

Nos palcos, Vestido de Noiva de Nelson Rodrigues contribui para a ascensão da modernidade cênica brasileira, e entre os espectadores comuns, críticos atentos a difundir a nova tendência. Contudo, os críticos teatrais não se restringiram a profissão que exerciam, mas assumiram também o exercício político na medida em que reivindicaram a emancipação da própria atividade e da arte teatral em diversas situações, inclusive na luta contra a censura. Através de pesquisa bibliográfica e documental percorremos esse importante trajeto histórico, reconhecendo principalmente, que a criação de organizações institucionais no Rio de Janeiro e em São Paulo, denominadas $A B C T, C I C T$ e APCT foram ações determinantes em prol destes objetivos.

Palavras-chave: Modernidade cênica; críticos teatrais; Nelson Rodrigues; teatro brasileiro

\section{Abstract}

On stage, Wedding Dress Nelson Rodrigues contributes to the rise of Brazilian scenic modernity, and among ordinary viewers, critics attentive to spread the new trend. However, theater critics were not restricted profession exercising, but also made a political exercise in that claimed the emancipation of the activity itself and theatrical art in various situations, including the fight against censorship. Through bibliographical and documentary research go through this important historical path, recognizing mainly the creation of institutional organizations in Rio de Janeiro and São Paulo, called ABCT, CICT and APCT were decisive actions towards these goals.

Keywords: scenic modernity; theatrical critics; Nelson Rodrigues; Brazilian theater
ISSN: 1414.5731

E-ISSN: 2358.6958
1 Mestre em Artes Cênicas pela Universidade Federal do Rio Grande do Norte (UFRN). $\quad$ erickalinelima@hotmail.com
2 Profa. Dra. Adjunta da Universidade Federal do Rio Grande do Norte (UFRN). nairaciotti@gmail.com 
No Brasil, em meados da década de 1940 a 1960, a crítica teatral garante seu espaço nas colunas jornalísticas, em um período em que o jornal impresso tornase o mais popular veículo de comunicação, pois adota "a crítica como um guia de consumo para o leitor, que compra o jornal para escolher o prato que vai comer e a peça que vai assistir" (Moura, 1996, p. 165), sendo uma atividade assiduamente acompanhada, por leigos e artistas. Com objetivo de compreender o ofício crítico, especialmente em um período tão importante para o cenário teatral, nos dirigimos a uma pesquisa bibliográfica e documental, reunindo os acontecimentos determinantes e depoimentos dos críticos desse período, observando, portanto, a modernidade teatral em um contexto mais amplo do que se conhece comumente, pela ótica de espectadores críticos.

Neste artigo, veremos que os críticos não se restringiram a profissão que exerciam, mas que assumiram, dentre outras circunstâncias, o exercício político na medida em que reivindicaram a emancipação da própria atividade e, principalmente da arte teatral. Esta que permanecia, até então, estagnada em moldes ultrapassados de técnica e estética, na realidade "a produção artística nos palcos brasileiros apresentou um atraso de quase duas décadas em relação às outras artes, que se destacaram nos anos 20 e 30" (Riego, 2006, p. 70).

Nesse sentido, destacaremos um dos marcos da modernidade cênica: a encenação da obra dramatúrgica Vestido de Noiva do jornalista e dramaturgo Nelson Rodrigues (1912-1980) estreada no Rio de Janeiro, em 28 de dezembro de 1943. É importante frisar que, na verdade, sempre houveram opiniões divergentes sobre como a modernidade nos alcançou, devido outras obras terem impactado o público brasileiro e a crítica, como O rei da vela de Oswald de Andrade em 1937, por exemplo. Algo que nos sugere considerar uma progressão e, não um surgimento abrupto das novas tendências. Contudo, a peça rodriguiana também faz parte desse traçado percorrido, e talvez por ser a mais conhecida e citada nos livros de história de teatro, seja tratada como a pioneira. Para Mostaço, "Houve sim, para a mentalidade moderna, a necessidade de fixar balizas, de estourar a monotonia dos relógios, pois todas as revoluções modernas almejaram iniciar um novo calendário, um simbólico ano zero de renovação" (2015, p. 256).

Mas o motivo que nos leva a refletir sobre Vestido de Noiva e mencionar outras obras de Nelson Rodrigues neste artigo, deve-se a crescente relação que esse autor demonstrou ter com a crítica - questões que serão expostas mais a frente - inclusive mediante às ações da censura que se encontrava fortemente ativa nesse período. Sendo possível construir um entendimento de como se organizava a crítica perante o contexto cênico moderno.

No campo da crítica havia a intenção de promover a modernidade teatral juntamente com o reconhecimento legal de sua atividade, por isso, a mobilização dos críticos fundaria Organizações Institucionais: a ABCT (Associação Brasileira de Críticos Teatrais); CICT (Círculo Independente de Críticos Teatrais) ambas no Rio de Janeiro; e, posteriormente em São Paulo, a APCT (Associação Paulistana de Críticos Teatrais). Mediante isso, que participação teve a crítica e as instituições ligadas a esta atividade na consolidação da modernidade teatral brasileira nos respectivos Estados? Quem foram os críticos desta época que abraçaram a causa por uma produção Teatral dife- 
rente reivindicando mudanças políticas para o setor artístico?

A crítica afirma seu lugar ao acompanhar as necessidades da arte, então, a tendência modernista seria da mesma maneira desejada e manifestada nas produções críticas. Em outras palavras, diretamente proporcional às novas perspectivas suscitadas pela arte moderna, a crítica também buscaria renovar-se e adquirir força enquanto ferramenta de análise e registro. Essa necessária adequação auxiliaria no processo de difusão da modernidade para as produções artísticas seguintes, pois estaria disseminando os estilos e as técnicas empregadas. Com isso, almejava-se cada vez mais nas colunas culturais dos jornais impressos conteúdos que abarcassem em suas entrelinhas:

Análises minuciosas dos elementos dos espetáculos, disponibilizando não somente informações ao público em geral, mas também promovendo um feedba$c k$ com os envolvidos na sua produção (direção, atores, iluminação, cenografia, etc.). [...] Assim sendo, o jornalismo impresso nesse período caracteriza-se por essa elitização dos conteúdos, uma tentativa de forjar uma tradição na vida intelectual dos grandes centros urbanos [...] (Freitas, 2010, p. 30-31).

Por reconhecer a importância da atividade crítica, e mais, por tentar promover critérios para seu exercício, críticos se uniram em prol da criação de um sindicato próprio. Surge em 1937, a Associação Brasileira de Críticos Teatrais - ABCT, com sede no Rio de Janeiro, integrado por Mário Nunes, Aldo Calvet, Augusto de Freitas, Paschoal Carlos Magno, Bárbara Heliodora, dentre outros. Buscava-se com essa instituição unir esforços para sintetizar meios de transformações no âmbito teatral, que por sua vez, enfrentava um momento de crise, devido a crescente preferência do público pelo cinema, e pelo fato das obras cênicas se resumirem, nesta época, à Comédia de Costumes e ao Teatro de Revista. Por esse motivo a Associação pleiteava:

[...] a criação de companhias oficiais, a construção de casas de espetáculos, a abolição das taxas e impostos incidentes sobre a produção teatral, a fundação de escolas especializadas, a regulação dos direitos dos profissionais da área, entre outras (Camargo, 2012, p. 156).

Entre tais reivindicações, a ânsia pela modernização cênica, semelhante a que incandescia toda Europa desde 1887 por meio, primeiramente, do Thêatre Libre de Antoine Artaud (Roubine, 1998). Tamanho movimento artístico representava uma experiência diferenciada na atividade teatral que precisava chegar ao Brasil por indicar uma forma de pensar e fazer teatro completamente distinto do habitual. Considerava-se a importância dos elementos cênicos - iluminação, figurino, texto, cenografia - e suas funções autorais no processo criativo, em uma harmonia a ser atingida pela regência do encenador. De acordo com o teatrólogo Jean-Jacques Roubine:

O encenador pelo fato de que a sua obra é outra coisa - e é mais - do que a simples definição de uma disposição em cena, uma simples marcação das entradas e saídas ou determinação das inflexões e gestos dos intérpretes. A verdadeira encenação dá um sentido global não apenas à peça representada, mas à prática do teatro em geral. Para tanto, ela deriva de uma visão teórica que abrange todos os elementos componentes da montagem: o espaço (palco e plateia), o texto, o espectador, o ator (1998. p.24). 
A razão pela qual Vestido de Noiva obteve o reconhecimento de obra moderna, se deve justamente, por sua inovadora estrutura dramatúrgica que foi muito bem transposta cenicamente pelo encenador polonês Zbigniew Ziembinski, que contou com o importante auxílio do grupo Os Comediantes, artistas que tinham em comum a vontade de produzir um teatro nacional diferente daquilo que estava sendo produzido até então. Sobre a participação de Ziembinski, George Moura (1996, p.41) nos revela:

Zbigniew Ziembinski, leva à cena um espetáculo com três planos de ação - realidade, memória e alucinação - 140 mudanças de cena, 132 efeitos de luz, 25 atores e 32 personagens. A peça Vestido de Noiva de Nelson Rodrigues nesta montagem se tornaria o divisor de águas para a entrada na modernidade cênica do Teatro Brasileiro.

Nos três planos simultâneos atrelados à trama: realidade, memória e alucinação; desenvolve-se a história de Alaíde que, logo na primeira cena, é vítima de um atropelamento. Devido ao acidente, a personagem encontra-se inconsciente e o leitor/espectador tem contato com o plano da memória mescladas com alucinações, a partir delas, os reais desejos, fatos de sua vida e a verdade vão sendo aos poucos desvelados. Agora imaginemos esses planos sendo ricamente colocados em cena, enfatizo, simultaneamente.

Compreendendo, portanto, às características que fizeram dessa peça o estopim da modernidade teatral é possível problematizar a postura dos críticos durante esse período e a importância que eles davam a esse movimento artístico. Sobre a estreia de Vestido de Noiva, o crítico Lopes Gonçalves escreve em 4 de janeiro de 1944 um longo texto para o jornal Correio da Manhã, observe um trecho de sua reflexão:

Até onde irá o sr. Nelson Rodrigues! Não sei com clareza, nem ele tão pouco, mas pressinto que caminhará por onde poucos têm passado, conduzido por essas forças íntimas [...] forças que, quando conjugadas, nos fazem enxergar as coisas e os fatos como se subitamente se tornassem transparentes. Não vou discutir detalhes de Vestido de Noiva, porque isso não importa para o caso, que é o de não oferecer dúvidas ser essa peça um acontecimento de larga significação para o nosso teatro ${ }^{3}$.

Com poucos dias após a estreia às características inovadoras da representação ressoava de forma unânime nas críticas. Nelson Rodrigues rompeu com as convenções temporais e espaciais, promulgando uma liberdade de criação que influenciaria os artistas brasileiros. Como Magaldi nos revela em sua observação crítica sobre a obra:

[...] através da aparente desordem dos planos, estrutura-se uma lógica inquestionável. A fragmentação das cenas leva não a unidade rotineira mas a uma arquitetura superior, em que as audaciosas se fundem numa última harmonia poética. Aproxima-se Vestido de Noiva, por isso, da técnica expressionista, na qual os diálogos são sincopados, telegráficos, situando os sentimentos e as emoções já no

3 Trecho retirado de documento original digitalizado, disponibilizado pela Biblioteca Nacional Digital do Brasil. Disponível em <http://memoria.bn.br/DocReaderl DocReader.aspx?bib=089842 05\&PagFis=18923\&Pesq=Vestido\%20de\%20noiva> Acesso em 22 de abril de 2016 
O teatro moderno brasileiro teve a ajuda de um estrangeiro para seu progresso, o fato é que historicamente - nesse período - haviam muitos artistas, às vezes companhias teatrais inteiras se refugiavam dos conflitos políticos existentes em seus países se instalando no Brasil, Ziembinski foi um deles. Em contraponto, haviam também, críticos teatrais que buscavam aperfeiçoar suas técnicas de análises por meio de viagens a consagrados centros de formação teatral, localizados principalmente nos Estados Unidos e Europa. O contato com o Teatro de outros países os aproximavam da real modernidade cênica, essa experiência garantia-lhes, além do conhecimento, a habilidade para reconhecer e propagar estas vivências em sua terra natal.

Um destes foi o crítico Celestino Silveira que recém-chegado dos Estados Unidos defendia arduamente a profissionalização do crítico, esta atividade que hospedada pela prática jornalística, tinha por redatores, na maioria das vezes, pessoas inexperientes que movidas somente pelo "gosto ou não gosto" exerciam a atividade crítica teatral. Como ele nos diz:

É preciso dizer que a independência da crítica americana a nossa crítica não tem? Agora, com a renovação que surge, também a crítica mais segura vem aparecendo. Há necessidade, porém, de especialização. Enquanto a crítica for considerada um "bico", não pode haver perfeição. Tudo depende dos diretores de jornais. Ainda a maioria dos críticos são redatores que exercem aquelas funções porque gostam de teatro (Diário de Notícias, 25/05/1946. In: Pereira, 1998, p.169).

O fato de ter ocorrido a discrepante existência de críticos publicitários, segundo George Moura (1996), era consequência das facilidades em se tornar um membro da $A B C T$, bastava escrever uma única vez, e então, se firmava como um membro eterno, possuindo até direito a voto em importantes premiações, inclusive na escolha dos melhores críticos do ano. Por mais que estivesse entre os planos - como foi visto nos primeiros parágrafos deste artigo - a intenção de trazer a modernidade teatral aos palcos brasileiros, a falta de controle da associação em estabelecer pré-requisitos para aqueles que entravam na associação, indicou a decadência das atividades da $A B C T$, pois muitos dos críticos sérios se desvincularam contribuindo assim para a futura extinção da entidade. E o conflito entre a Velha e Nova Geração de críticos iniciava:

\footnotetext{
De um lado, críticos aliados ao velho modelo de teatro: incapazes de fazerem julgamento mais severo sobre determinadas peças, colocando suas amizades em primeiro plano e chegando até mesmo a receber propinas para escreverem algo positivo. Do outro, uma crítica nascente que ambicionava rígidos padrões de avaliação e isenção total ao comentar os espetáculos (Pereira, 2004. p. 19).
}

Apesar de renomados críticos fazerem parte da $A B C T$, tais fatores contribuíram para o seu eventual desgaste, e a consequente "migração" de boa parte destes críticos para outro grupo em formação. Surge então, em 1950, o Círculo Independente de Críticos Teatrais - CICT, também conhecido como a nova geração de críticos teatrais. O motivo da existência "foi a discordância de alguns críticos em relação aos cri- 
térios adotados pela ABCT (Associação Brasileira de Críticos Teatrais)" (Moura, 1996, p. 50).

O grupo lutava pela seriedade da profissão, onde almejavam críticos que realizassem seu trabalho sem que intencionalmente favorecessem alguma empresa teatral, com interpretações manipuladas para empreender divulgação. Mas, que levassem em consideração a realidade vivenciada e sentida nos teatros brasileiros, em análises verídicas e objetivas:

[...] o crítico da Nova Geração [...] era uma pessoa dada às leituras das obras fundamentais do teatro contemporâneo e que via no contato com os espetáculos de grandes companhias estrangeiras um parâmetro a ser alcançado pelo teatro nacional (Moura,1996, p. 52).

Entre os participantes do CICT, estava Bárbara Heliodora (1923-2015) membro da $A B C T$, que não só participou da criação do Círculo Independente, como também o presidiu. Em entrevista à Revista Trópico, Heliodora diz que o CICT foi organizado pelos críticos atuantes da época, para fazer parte do grupo era necessário que o crítico estivesse assinando uma coluna, caso ficasse desempregado poderia continuar, porém não teria direito a voto em premiações da área. Segundo Bárbara Heliodora, o CICT era um grupo pequeno, mas todos somavam esforços a fim de tornar a crítica uma atividade, sobretudo, responsável.

Da mesma forma pensava o crítico Paulo Francis (1930-1997) que não media palavras para retratar o objeto analisado: a prática teatral. Suas palavras se revelavam como verdadeiras "agulhadas" para muitos artistas, que ressentidos não tardavam a revidar o golpe. Francis estudou na Universidade de Columbia, nos Estados Unidos, onde teve como mestre Eric Bentley a lhe ensinar Literatura Teatral Comparada. Segundo o próprio Francis, "Eric Bentley me ensinou como pensar uma peça" (Francis apud Moura, 1996, p.36). Retornando ao Brasil em 1957, então, com 27 anos, engaja-se como diretor teatral, colocando em prática as experiências vivenciadas em seu contato com o teatro estadunidense, em seguida, envereda pelos caminhos da crítica.

Em suas críticas, expostas nos jornais Diário Carioca e Correio da Manhã, Francis se torna conhecido por suas análises e opiniões que causavam conflitos e polêmicas, mas que se determinavam pela forte análise. Não é de se estranhar que ele tenha enveredado pelo ativismo da crítica em favor de um Novo Teatro, abraçando as causas do $C I C T$. A rivalidade entre $A B C T$ e $C I C T$, na cidade carioca, estruturava-se também número de redações jornalísticas que seus membros trabalhavam, "segundo uma coluna de Paulo Francis sem data e provavelmente do jornal a Última hora, [...] o CICT dominava praticamente a totalidade dos jornais cariocas, enquanto outrora poderosa ABCT contava apenas com o diário A noite" (Brandão, 2002, p.179).

Já os críticos atuantes em São Paulo, outra metrópole que se destacava pela intensa movimentação artística - tal como a capital carioca - necessitava de um órgão de representação. Em 1956, inauguram a Associação Paulista de Críticos Teatrais - APCT, considerada uma entidade mais ativa em termos políticos em relação às já mencionadas, tendo entre os integrantes, os críticos Décio de Almeida Prado e Sábato Magaldi. Décio presidiu a entidade na busca por melhorias no setor cultu- 
ral, chegando inclusive, a "solicitar ao então governador Jânio Quadros a criação da Comissão Estadual de Teatro, para planejar a atuação do Estado nessa área artística" (Garcia, 2000, p. 94), além dessa reivindicação, outras foram atendidas.

O modo de pensar e agir do crítico Décio de Almeida Prado (1917-2000), em relação aos vários assuntos que envolviam o desenvolvimento teatral daquela época, seja político ou artístico, conferiu a importância que até hoje lhe é honrada. Como um dos mais influentes críticos, exerceu também a posição de professor, cronista, ensaísta e historiador. "Suas críticas tinham não somente a qualidade de informar, esclarecer, instruir o público, mas também, dentro de um critério objetivo, fundamentado, respeitoso, mas sem concessões, esclarecer os criadores do espetáculo" (Garcia, 2000, p.93). Para termos uma noção de como se configurava a crítica deste autor, observemos um trecho sobre a encenação de Vestido de Noiva, Décio Prado escreve uma crítica para a Revista Clima, texto publicado em agosto de 1944:

Causa mesmo espanto ver surgir do nada que é o nosso teatro, quase por um milagre de geração espontânea, um autor com tanta audácia, que procura, logo nas primeiras tentativas teatrais, dominar virtuosisticamente o meio de expressão artística que escolheu. [...] Ele procurou as dificuldades, como que para mostrar os próprios recursos, preferindo, em lugar de uma construção simples e linear, construir sua peça seguindo as tortuosidades do delírio de uma mulher de psicologia complexa, e que, além disso, sofreu um choque e está às portas da morte (Prado apud Navarro, 2010, p. 28).

Outro importante pilar da crítica teatral paulistana foi Sábato Magaldi (19272016) além de jornalista, um ávido pesquisador da área, contribuindo amplamente para a formação histórica do teatro brasileiro. Trouxe em suas críticas uma cordialidade que não confrontava, nem reprimia, expondo sua interpretação analiticamente, sendo reconhecido pelas vastas pesquisas em torno da obra de Nelson Rodrigues. $\bigcirc$ próprio dramaturgo definiu Sábato, após ler uma crítica dele, a respeito da montagem de sua peça Viúva, porém honesta (1957):

[...] leio a crítica do Sábato Magaldi. Ora, nem a cambaxirra tem uma estrutura tão doce quanto o Sábato. Até sua restrição é um arrulho. E ele tem o medo, o remorso, a vergonha, a pena de não gostar. Apesar de todo o seu escrúpulo crítico e de toda a doçura de sensibilidade, sente-se que o Sábato achou abominável o espetáculo. Não chega a tanto, mas a insinuação é límpida (Rodrigues, 1993, p. 229).

Sábato também se mostrou um ativista teatral no momento que o teatro brasileiro buscava à modernidade, pois além de todas as questões que se mostravam como objetivos a serem alcançados na união entre artistas e críticos, houve o embate direto com a Censura. Logicamente, todos os setores artísticos foram igualmente acometidos pelas ações do órgão repressor, que se manteve implacável antes e durante o período da ditadura militar.

Um exemplo disso, podemos reconhecer em outra obra do autor moderno Nelson Rodrigues, conhecido por trazer em suas peças temáticas fortes (assassinatos, suicídios, incestos, prostituição...) e que, por isso, se chocavam com os ideais morais 
que regiam o estatuto da censura. Perdoa-me por me traíres (1957) nos serve como exemplo, pois é dentre todas do acervo do autor uma das mais polêmicas no arquivo da censura paulistana. A peça traz em seu conteúdo, incesto, prostituição, aborto, assassinato e suicídio o que escandalizou a sociedade conservadora e a censura na época.

Foram emitidos diversos pareceres, vários censores foram chamados, o governador Jânio Quadros interviu liberando a representação, mas voltou atrás interditando novamente, por pressão da Associação das Senhoras Católicas - que reuniram mais de 3.000 assinaturas contra a obra. Diante disso, a Classe teatral da cidade toma a causa do dramaturgo e também reúnem assinaturas de vários artistas e críticos importantes da época, repudiando a decisão da censura. Como podemos ver na imagem, retirada do processo censório ${ }^{4}$ da referida peça:

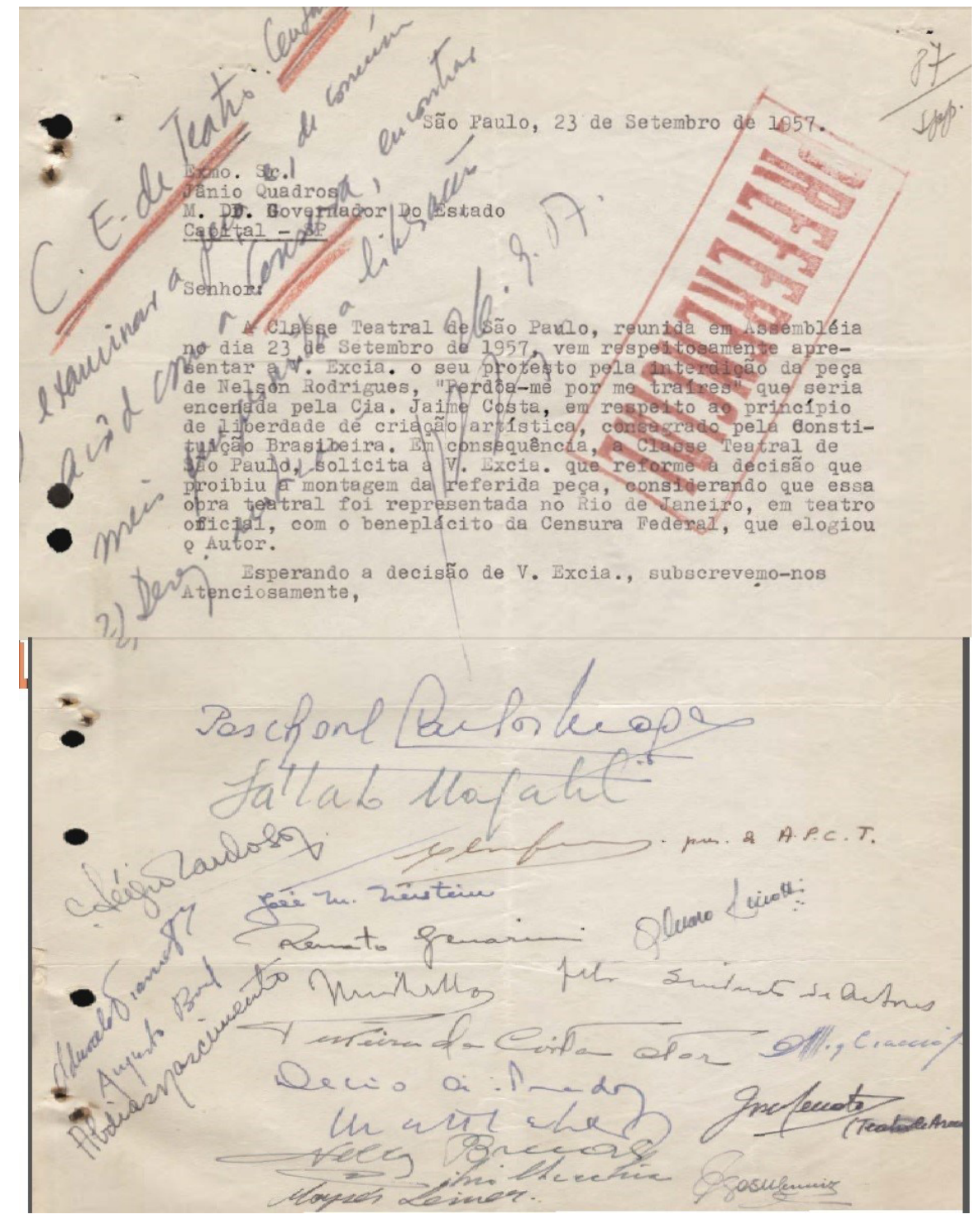

Figura 1- Resposta da Classe Teatral a interdição da peça Perdoa-me por me traíres. Fonte: Arquivo Miroel Silveira - AMS/USP

$4 \mathrm{O}$ acesso a esse processo de Censura referente a obra Perdoa-me por me traíres de Nelson Rodrigues, foi possível por meio do Arquivo Miroel Silveira, localizado na Universidade de São Paulo - USP. 
A APCT mostrou além da solidariedade ao acontecimento vivenciado pelo dramaturgo, um apoio fortemente político revelando sua indignação a qualquer tipo de atentado à liberdade de expressão e aos direitos dos artistas. Como é possível identificar na figura 1, dentre as assinaturas de artistas como Augusto Boal, encontra-se as dos críticos Sábato Magaldi, Décio de Almeida Prado, Paschoal Carlos Magno dentre outros da associação paulistana.

As atitudes da Associação Paulista - APCT, representado por Décio Prado, serviu também como parâmetro para o CICT gerar seus objetivos em meio ao embate entre gerações que enfrentava no Rio de Janeiro, por isso, sistematizou sua luta em torno da especialização, rigor técnico e seriedade na atividade crítica. Desse modo, a força política demonstrada pela APCT desde a sua fundação, a fez se tornar em 1972 a Associação Paulista de Críticos de Arte - APCA, ou seja, os interesses que antes eram voltados somente para o Teatro, agora contemplavam as outras áreas artísticas: Música (erudita e popular), Dança, Artes Plásticas, Literatura, Cinema e Televisão.

Configura-se, então, o exercício crítico fomentado pela seriedade de uma profissão. Logo, os críticos se tornariam figuras indispensáveis para disseminação cultural da sociedade, e mais ainda, para o artista que ansiava o reconhecimento de sua obra por meio de uma análise meticulosa - mas que nem sempre o agradava. Podemos ver que Nelson Rodrigues, enquanto artista desse período de confrontos, também tinha sua opinião sobre aqueles que analisavam a obra, demonstra que até mesmo o crítico que tem seus textos como obra, está sob olhar analítico de seus leitores:

Quanto à crítica, Sábato Magaldi é o único crítico de teatro que nós temos. Yan Michalski é um belo nome para violinista húngaro. Henrique Oscar, nem ao menos um belo nome, nunca existiu. Paulo Francis, o teatro dramático nos separou, o teatro lírico nos uniu. Ele pelo menos tem a coragem suicida de dizer o que pensa. A crítica de cinema ainda é pior. A crítica literária idem. Antônio Candido é o falso grande crítico (Rodrigues, 2011, p. 166).

O crítico teatral Paulo Francis, já mencionado anteriormente, defendia a ideia do crítico em um mesmo patamar do artista, por ser capaz de sugerir caminhos precisos para aperfeiçoamento da obra, e ter a preocupação de orientar o público, concedendo informações que servem de base analítica no momento de contemplação. Contudo, ao instaurar no meio artístico a crítica nos moldes do CICT, a relação entre artista e crítico passa a se fragilizar, como elucida Paulo Francis em seu artigo "Ervas daninhas" de 5 de fevereiro de 1965:

[...] O raciocínio de profissional de teatro, por mais sério que seja, é dual. Em parte, ele respeita a crítica séria no que tem de afim com seu trabalho. Ele próprio se critica e aos companheiros com severidade. Mas, para efeito público, teme o crítico. Não quer ver seu nome maltratado no jornal, ainda que com justiça. $\mathrm{O}$ crítico amigo aí se torna útil. O profissional o despreza na intimidade, mas usa-o como propaganda. Já o crítico sério é, quando muito, uma espécie de rival. Equivale à consciência de quem faz teatro, exerce um policiamento que não gostamos de permitir a ninguém, que frequentemente, quando nos iludimos a nós mesmos, não permitimos a nós próprios (Francis apud Moura, 1996. p.80-81).

Essa reflexão proferida por Francis na década de 60 não se torna ultrapassada 
frente ao momento atual, aliás, a frágil relação entre artista e crítico foi uma das consequências do rigor que tanto anunciavam os críticos. Não se pode dizer que hoje se faz o mesmo tipo de crítica que o final do século $X X$, o que se pode averiguar é que as fases de evolução da crítica, da publicitária à análise ferrenha, foram essenciais para torná-la uma atividade versátil e completa. Além disso, o culminar da modernidade no meio artístico é um indicador para a crítica também se renovar.

Com a decadência da $\mathrm{ABCT}$, alguns críticos não tiveram receio em recomeçar do zero e acertar nos quesitos onde a antiga associação apresentava falhas. Assim nasceu o CICT, que por muito tempo esteve ativo rivalizando seu status com a $A B C T$, rivalidade alimentada por serem duas instituições ligadas ao mesmo setor, localizadas no Rio de Janeiro. Não é de se estranhar que vários historiadores tenham definido esse momento como uma batalha entre gerações de críticos. Em São Paulo, a APCT seria um exemplo a ser seguido pelas demais instituições vinculadas ao setor, inclusive para o próprio CICT, a liderança de Décio de Almeida Prado na Associação Paulista indicou o marco inicial do desenvolvimento da atividade crítica, e ainda, a valorização da profissão.

O valor preponderante da crítica é sua relação com a história. Como vimos, mediante a efemeridade da arte teatral, a partir dos escritos críticos se torna possível remontar dados da obra e eternizá-la. Os textos produzidos por Paulo Francis, Bárbara Heliodora, Décio de Almeida Prado e Sábato Magaldi - apresentados neste trabalho - inclusive os direcionados à montagem da obra Vestido de Noiva de Nelson Rodrigues, encenada por Ziembinski permite - por exemplo - tomarmos conhecimento como foi o espetáculo em suas primeiras montagens, sendo mobilizador do teatro moderno. Isto é, a crítica cumpre seu papel de perpetuar a obra, mesmo a arte mais efêmera, servindo assim de suporte para a história.

Em suma, vemos um período de transição, a arte teatral passa a se reinventar e agregar novos valores que, anterior à montagem da peça Vestido de Noiva, caracterizava-se pelo "teatro sem a figura do encenador, às vezes com a presença ainda do ponto e usando textos como meros pretextos para o histrionismo" (Moura, 1996. p. 48). A crítica também tem seu momento de ascensão, nesta época, caracterizado pela crescente reverberação do jornal impresso e o advento de críticos sérios que até hoje têm sua importância reconhecida. Estes, por estimarem tanto o progresso teatral, criaram fontes institucionais para se aproximar das questões políticas que tanto necessitavam a classe artística, priorizando a luta pela modernidade cênica e sua manutenção frente às ameaças de retrocesso advindas, principalmente, da censura.

\section{Referências}

BRANDÃO, Tânia. A máquina de repetir e a fábrica de estrelas: Teatro dos Sete. Rio de Janeiro: 7 Letras, 2002.

CAFEZEIRO, Carmem e GADELHA, Edwaldo. História do Teatro brasileiro: De Anchieta à Nelson Rodrigues. Rio de Janeiro: UFRJ, EDUERJ, FUNARTE, 1996. 
CAMARGO, Angélica Ricci. Em busca de uma política para o desenvolvimento do teatro brasileiro: as experiências da Comissão e do Serviço Nacional de Teatro (19361945). Rio de Janeiro, 2011. Dissertação (Mestrado em História) - Instituto de Filosofia e Ciências Sociais, Universidade Federal do Rio de Janeiro.

FARIA, João Roberto; AREAS, Vilma; AGUIAR, Flávio. Décio de Almeida Prado: um homem de teatro. São Paulo: FAPESP EDUSP, 1997.

FREITAS, Talitta Tatiane M. Critica em crise ou a crise da crítica. In: Por entre as coxias: A arte do efêmero perpetuado por mais de "Sete Minutos". 2010. Dissertação (Mestrado) - Programa de Pós-graduação em História, Universidade Federal de Uberlândia, Uberlândia, 2010.

GARCIA, Clóvis. Décio, Antes de tudo um Crítico Teatral. São Paulo. Revista ADUSP. Março-2000, p.92-94. Disponível em: <http://www.adusp.org.br/files/revistas/19/r19a16.pdf> Acesso em 13 jul. 2013.

MAGALDI, Sábato. Teatro da Obsessão: Nelson Rodrigues. São Paulo: Global, 2004.

MOSTAÇO, Edelcio. Considerações sobre História do teatro brasileiro. Revista sala preta,: USP. Vol. 15, n. 1, 2015.

MOURA, George. Paulo Francis, o soldado fanfarrão: A odisseia intelectual do ator, diretor e crítico de teatro Paulo Francis pelos palcos brasileiros. Rio de Janeiro: Objetiva, 1996.

RIEGO, Christina Barros. O teatro brasileiro nas revistas literárias e Culturais do modernismo: 1922 - 1932. Revista letras, Curitiba: Editora UFPR. n 68, P. 69-85, Jan./Abr. 2006.

RODRIGUES, Nelson; RODRIGUES, Sônia (Org.). Nelson Rodrigues por ele mesmo. 1.ed. Rio de Janeiro: Nova Fronteira, 2011.

ROUBINE, Jean-Jacques. A linguagem da encenação teatral. 2. ed. Rio de Janeiro: J. Zahar, 1998.

PEREIRA, Aline Andrade. Sobe o pano: a crítica teatral e sua legitimação através de Vestido de Noiva. (Dissertação de mestrado). Niterói: UFF, 2004.

PEREIRA, V.H. Adler. A musa carrancuda: teatro e Estado Novo. Rio de Janeiro: Editora Fundação Getúlio Vargas, 1998. 